NEW SOLUTIONS, Vol. 12(4) 409-423, 2002

\title{
INTERACTIONS OF PATHOGENS AND IRRITANT CHEMICALS IN LAND-APPLIED SEWAGE SLUDGES (BIOSOLIDS)
}

\author{
DAVID L. LEWIS* \\ DAVID K. GATTIE \\ MARC E. NOVAK \\ SUSAN SANCHEZ \\ CHARLES PUMPHREY
}

\begin{abstract}
Fertilization of land with processed sewage sludges, which often contain low levels of pathogens, endotoxins, and trace amounts of industrial and household chemicals, has become common practice in Western Europe, the United States, and Canada. Local governments, however, are increasingly restricting or banning the practice in response to residents reporting adverse health effects. These self-reported illnesses have not been studied and methods for assessing exposures of residential communities to contaminants from processed sewage sludges need to be developed. Methods: To describe and document adverse effects reported by residents, 48 individuals at ten sites in the United States and Canada were questioned about their environmental exposures and symptoms. Information was obtained on five additional cases where an outbreak of staphylococcal infections occurred near a land application site in Robesonia, Pennsylvania. Medical records were reviewed in cases involving hospitalization or other medical treatment. Since most complaints were associated with airborne contaminants, an air dispersion model was used as a means for potentially ruling out exposure to sludge as the cause of adverse effects. Results: Affected residents lived within approximately $1 \mathrm{~km}$ of land-application sites and generally complained of irritation (e.g., skin rashes and burning of the eyes, throat, and lungs) after exposure to winds blowing from treated fields. A prevalence of Staphylococcus aureus infections of the skin and respiratory tract was found. Approximately one in four of 54 individuals were infected, including two mortalities (septicemia,
\end{abstract}

*From www.biomedcentral.com/1471-2458/2/11 
pneumonia). This result was consistent with the prevalence of $S$. aureus infections accompanying diaper rashes in which the organism, which is occasionally found in the lower human colon, tends to invade irritated or inflamed tissue. Conclusions: When assessing public health risks from applying sewage sludges in residential areas, potential interactions of chemical contaminants with low levels of pathogens should be considered. An increased risk of infection may occur when allergic and non-allergic reactions to endotoxins and other chemical components irritate skin and mucous membranes and thereby compromise normal barriers to infection.

\section{BACKGROUND}

Class B biosolids, the most common form of processed sewage sludges used in agriculture, are treated to reduce levels of pathogens by various processes including anaerobic digestion and $\mathrm{pH}$ elevation (lime stabilization). The finished product may contain a wide variety of contaminants with a potential for adverse health effects [1]. This includes enteric bacteria, viruses, endotoxins, inorganic and organic sulfides, volatile fatty acids, alkyl amines, and ammonia [2, 3]. No formal pathogens risk assessment has been carried out for public exposure to Class B biosolids [4]; and, complaints of sludge-related illnesses reported by residents have not been previously studied.

Retrospective studies have been done on workers exposed to sewage sludges who have reported illnesses. Gregersen et al. [5], for example, investigated five workers who experienced fever and flu-like symptoms after repairing a decanter used for concentrating sludge at a sewage treatment plant. High concentrations of Legionella pneumophila (serogroup 1) found in the sludge along with positive antibody titers in all five workers indicated that they developed Pontiac fever from contact with sludge. Similarly, NIOSH investigated five workers complaining of headaches, stomach cramps, and diarrhea at a sludge processing operation [6]. Investigators isolated a variety of enteric, opportunistic pathogens from bulk sludge samples and airborne particulates, including species of the genera Mycobacterium, Pseudomonas, and Staphylococcus. Based on the nature and timing of their symptoms, investigators concluded that ingestion or inhalation of pathogens in sewage sludge probably caused the illnesses.

Dorn et al., on the other hand, found no elevated risks of infection in the only epidemiological study done with residents exposed to sewage sludges [7]. The authors of this prospective study, however, did not determine whether any pathogens were present in the material. Also, because of the low application rates used in the study, they cautioned against extrapolating their data to other sites.

Our retrospective investigation was designed to use a survey for describing adverse effects reported by residents, develop an approach for assessing their environmental exposures, and evaluate whether any infections associated with exposure to sewage sludges were prevalent within the group. 
BIOSOLIDS / 411

\section{METHODS}

\section{Surveying Residents}

To indicate the general symptomatology, we surveyed 48 affected residents at ten land-application sites in Alabama, California, Florida, New Hampshire, Ohio, Ontario, Pennsylvania, and Texas (Table 1). Questionnaires were patterned after a previous epidemiological study in Ohio and based on symptoms associated with exposure to sewage sludges $[6,7]$. More specifically, residents were queried about their symptoms and how much time elapsed between exposures and onset. Individuals who were previously questioned by environmental activists were excluded from the survey and medical records were obtained in cases involving death or serious illnesses (those requiring medical attention).

Using chi-squared analyses, proportions of individuals reporting a particular symptom at each site were compared with the combined reports for that symptom at all sites. $P$ indicated how consistently a symptom was reported from site to site, that is, the degree to which numbers of individuals reporting a particular symptom at a given site could be expected based on the frequency of that symptom for all sites combined. Low $P$ values were indicative of symptoms that were largely independent of confounding health-related and environmental factors (e.g., previous medical history, demographics, sources of biosolids, and environmental conditions).

This survey, which represents a collection of case studies, was primarily intended to describe and document self-reported illnesses. It also provided guidance on which exposure routes (e.g., contaminated drinking water, dermal contact, or inhalation of aerosols) should be the focus of the research. Exposure, on the other hand, was evaluated using a dose-response curve in a separate part of the study concerning environmental assessments.

\section{Assessing Environmental Conditions}

Sludges used at all but one agricultural site (Ontario), according to county records, were limed or applied to alkaline soils then exposed to weathering. Whether sludges used for mining reclamation in Osceola Mills were lime stabilized, however, was disputed. Residents reported that the area was limed after sludging.

County records indicated that biosolids-related complaints for individual patients described in this study were concurrent with land application of Class B biosolids. In the case of one family (Residents 19-22), however, records indicated that dairy wastes, rather than biosolids, had been applied. Unconfirmed reports that dairy wastes had been mixed with Class B biosolids prior to application at this site, however, precluded the authors from ruling out biosolids as a possible cause of the symptoms. According to county officials, soil in this area is 
412 / LEWIS ET AL.

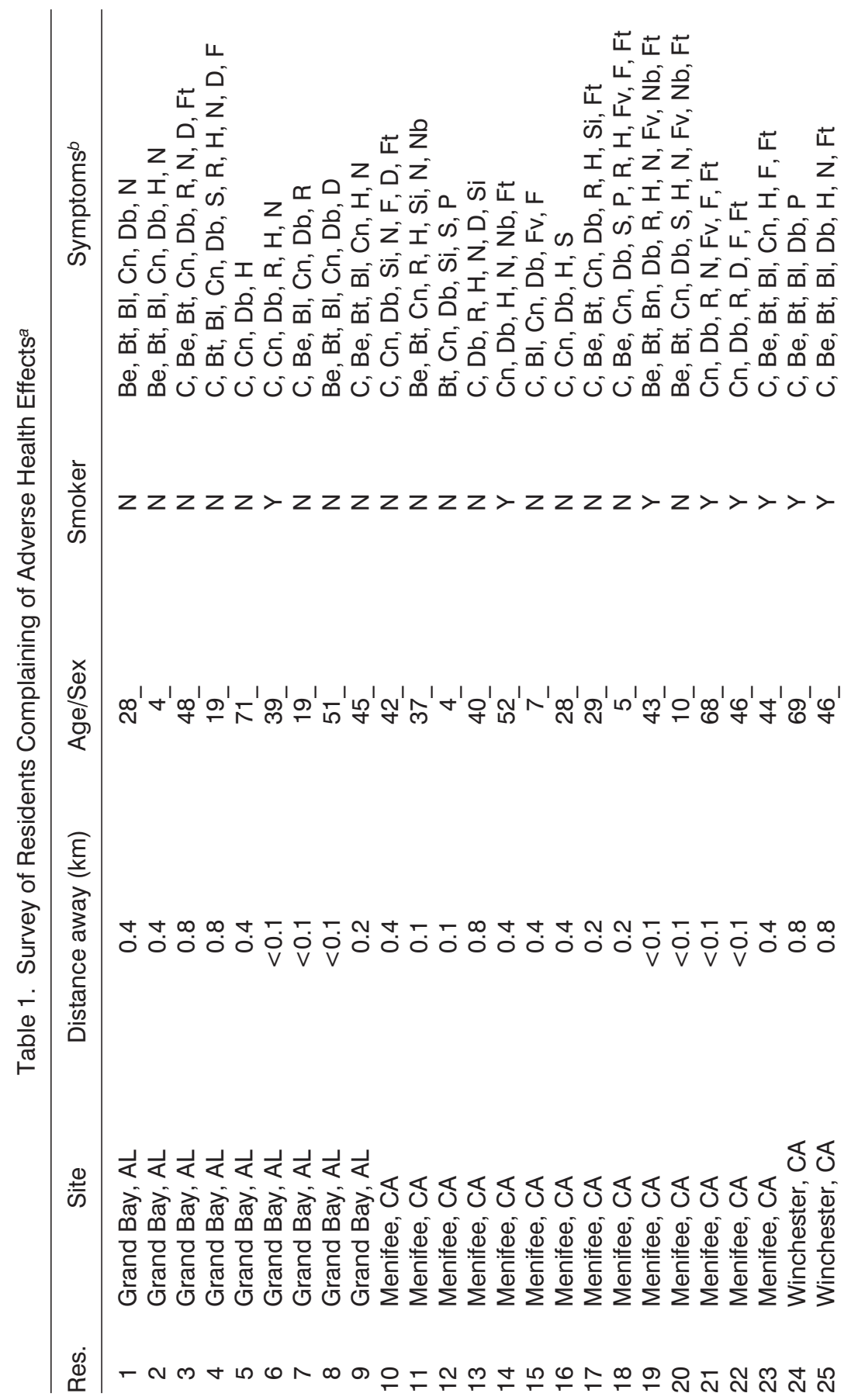


BIOSOLIDS / 413

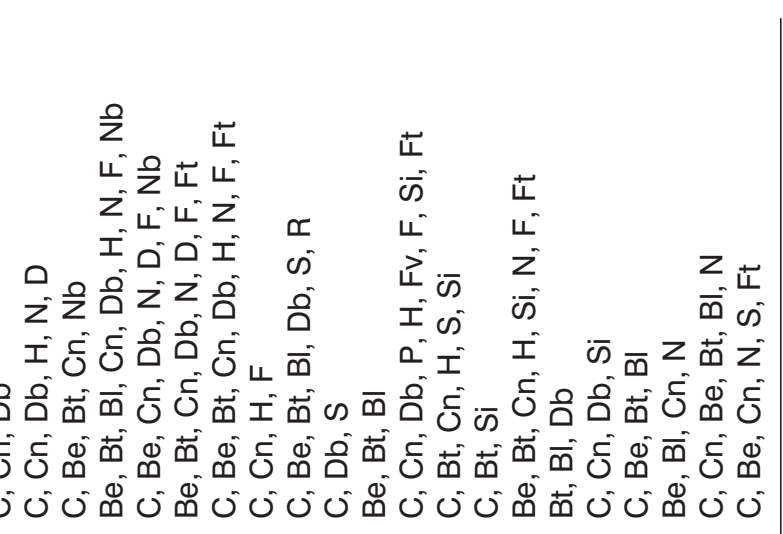

$>z z z z>z z>z z z z z z z z z z z z z$

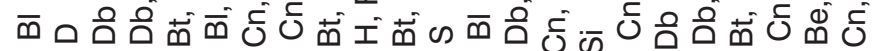

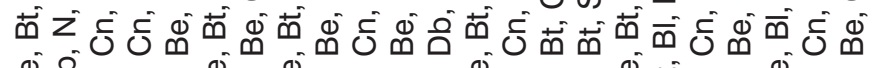

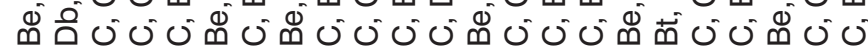

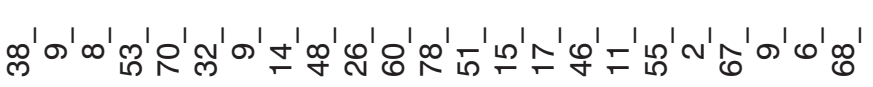

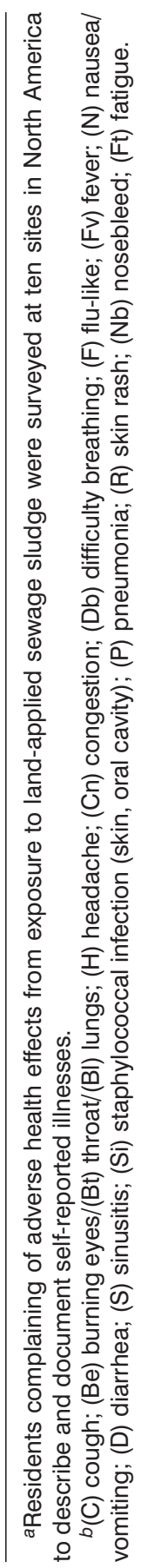

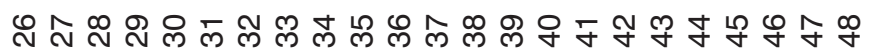

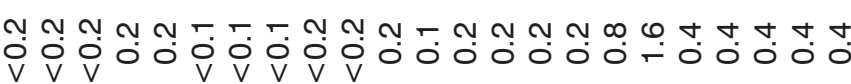

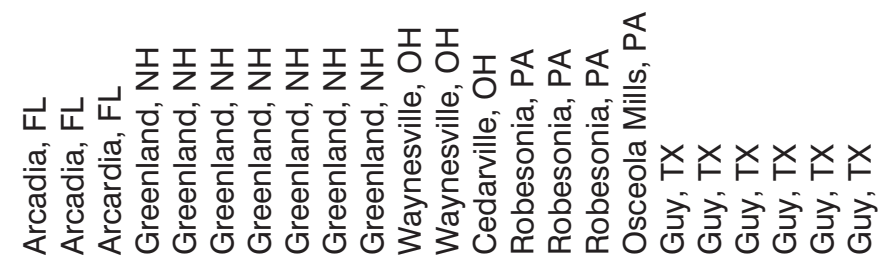


naturally alkaline such that irritation similar to that observed with exposure to lime-stabilized sludge may occur.

The New Hampshire site was used to develop an approach for assessing exposures to windborne contaminants. At the site, approximately 132 metric tons (dry wt) of Class B biosolids containing 12 metric tons of lime and $318 \mathrm{~kg}$ of Stockhausen 644BC cationic polymer (Stockhausen, Inc., Greensboro, North Carolina) were applied to a 10-ha field in late October 1995. The field was located at the end of a paved road with eight houses $(\mathrm{A}-\mathrm{H})$ and 28 residents.

Historical records of symptoms experienced in the neighbourhood were kept by one of the residents. Records began approximately 2 weeks after sludges were applied and continued for approximately two years (1995-96). Descriptions of symptoms included coughing, burning eyes, burning throat, congestion, and difficulty in breathing.

To evaluate wind conditions at the site at the time sewage sludge was applied, we used a computer program (WRPLOT Version 3.5, Lakes Environmental Corp., Waterloo, Ontario), topographic information, and historical weather data from Pease Air Force Base located approximately $5 \mathrm{~km}$ from the site. Exposure times (h), which were based on duration of wind passing directly from the field toward each house, were determined from wind frequency data averaged for three 8-day periods after sludges were applied (between October 31-November 23, 1995). Distances $(\mathrm{m})$ each household resided from the nearest edge of the treated field were 23 (A, B); 77 (C), 170 (D); 130 (E); $280(\mathrm{G})$; and $320(\mathrm{H})$.

Concentrations of air pollutants to which residents were exposed, relative to concentrations over the treated field, were predicted using an Industrial Source Complex (ISC3) Dispersion Model [8]. This prediction was not specific for any pollutant. Instead, it was used as a means for possibly ruling out the effects of ammonia, organic amines, or other gaseous or volatile pollutants. Should airborne chemical contaminants be present only at a fraction of a percent of the concentrations present over the treated field, the result would argue against airborne chemical pollutants as a cause of adverse effects. If, on the other hand, pollutants are sufficiently concentrated to cause burning eyes and other symptoms of irritation at the application site, these same effects may occur among residents in areas where pollutant concentrations are not highly diluted.

The ISC3 air dispersion model is designed to predict concentrations of pollutants off site based on emission rates of the pollutants at their sources and local meteorological conditions. This approach is unreliable when emission rates cannot be accurately determined. Microbiological process rates, which largely control emission rates of airborne pollutants produced by sewage sludges, are highly unpredictable. To circumvent this problem, the model was used only to predict the relative concentrations of air pollutants between the treated field and potentially affected residences. This approach is based on the dispersion of air pollutants as winds carry them over land surfaces, irrespective of their emission rates at the source. 
BIOSOLIDS / 415

\section{RESULTS}

\section{Residents Survey}

Demographic data for the 48 residents surveyed, along with their symptoms, are listed in Table 1. The average age of the group was 35 years; 56 percent were female; 23 percent were smokers. Residents who complained of adverse effects lived within approximately $1 \mathrm{~km}$ of the treated fields. Symptoms were primarily associated with sites where freshly applied, lime-stabilized sewage sludges remained on the surface and were exposed to wind erosion.

The primary complaints (a fourth or more reporting the symptom) within $1 \mathrm{~h}$ of exposure were coughing (63 percent, 8 sites), burning throat (56 percent, 10 sites), burning eyes (56 percent, 9 sites), and headaches (46 percent, 6 sites). Within $24 \mathrm{~h}$, residents developed nasal and chest congestion ( 77 percent, 7 sites), difficulty in breathing ( 71 percent, 8 sites), nausea/vomiting (46 percent, 7 sites), fatigue (33 percent, 7 sites), and flu-like symptoms ( 29 percent, 5 sites). In some cases, symptoms of chemical irritation (e.g., burning eyes, burning throat) recurred for over a year after applications ceased.

Proportions of individuals reporting coughing and burning throats exhibited the greatest consistency from site to site ( $P 0.02,0.03$, respectively). Half of the residents reported bacterial, viral, or fungal infections within one month of exposure (50 percent, 8 sites). Most residents also reported symptoms indicating exposure to infectious micro-organisms or microbial products (endotoxins). These included flu-like symptoms ( 29 percent, 5 sites), nausea/vomiting (46 percent, 7 sites), diarrhea ( 21 percent, 4 sites), rashes ( 25 percent, 3 sites), and sinusitis (19 percent, 5 sites).

The most common infections identified by medical records were caused by $S$. aureus (14 residents at 3 sites, including the additional patients identified in Robesonia). Records indicated that one infection (S. lugdunensis, Resident 44) was probably hospital-acquired. Affected residents in Greenland, New Hampshire, recalled that respiratory infections experienced by individuals in several households treated by the same physician responded to erythromycin, an antibiotic primarily used for treating gram positive bacterial infections.

In Menifee, California, two family members complaining of chemical irritation developed different staphylococcal infections. Resident 17 experienced recurrent $S$. aureus infections of the nasal passages and oral cavity. The spouse was hospitalized for an invasive $S$. epidermitis infection that developed approximately two days after an undressed surgical incision became contaminated with sand blowing from an adjacent field treated with Class B biosolids.

Mild chronic maxillary sinusitis in one child (Resident 18) living in this household deteriorated into recurrent (unidentified) bacterial infections. The patient responded poorly to oral and IV antibiotic therapy, tonsillectomy, and 
removal of the adenoids. Rigorous antibiotic therapy, including intramuscular injections of rocephrine, also yielded unsatisfactory results.

County records showed that Class B biosolids were applied to an adjacent field at the time the above-mentioned illnesses developed. The pediatrician treating patients in the area (author C. Pumphrey) noted that children living near the land application sites appeared to develop abnormally persistent sinusitis.

\section{Environmental Assessment}

Samples of sludges collected at the New Hampshire site, which were frozen since 1995, retained a strong fecal odor. Microbiological assays showed that they contained $(3.2 \pm 3.5) \times 10^{5}$ colony-forming units of bacteria per gram but almost no culturable fungi. Predominant culturable bacteria were identified as common gram-negative environmental isolates and included Alcaligenes faecalis and Brevundimonas diminuta, which occasionally serve as opportunistic human pathogens.

Exposure times (h) for each household when initial symptoms of chemical irritation were reported (October 31-November 23) were: $28 \pm 25$ (A); $48 \pm 17$ (B, C); $21 \pm 12$ (D); $88 \pm 17(\mathrm{E})$; and $13 \pm 08(\mathrm{G}, \mathrm{H})$ (mean \pm standard deviation, $n=3)$. The air-dispersion model indicated that adverse effects from exposure to airborne pollutants from the land-application site could not be ruled out as a cause of adverse health effects. Air pollutants at Household C, for example, were frequently present at concentrations of approximately 5 to 40 percent compared with concentrations $2 \mathrm{~m}$ directly above the treated field (Figure 1).

Numbers of individuals who reported adverse effects compared with the total numbers of individuals per household, respectively, were: 2, 2 (A); 2, 2 (B); 5, 5 (C); 2, 3 (D); 4, $4(\mathrm{E}) ; 1,3(\mathrm{G})$; and 1, $5(\mathrm{H})$. Data from one household (F) were unavailable. Based on a least-squares analysis, proportions of individuals with symptoms increased linearly from 40 to $80 \mathrm{~h}\left(\mathrm{r}^{2} 0.98\right)$ with time exposed to wind blowing from the field; all occupants in households with exposure $\geq 80 \mathrm{~h}$ reported symptoms (Figure 2). Proportions of individuals with symptoms also decreased linearly with distance from the field from 130 to $320 \mathrm{~m}\left(\mathrm{r}^{2} 0.95\right)$; all occupants in households living $\leq 130 \mathrm{~m}$ from the field reported symptoms.

\section{Prevalence of S. aureus infections}

Two cases involving mortality from $S$. aureus occurred with individuals who directly contacted freshly applied biosolids. In the first case, an 11-year-old male in Osceola Mills, Pennsylvania with an unremarkable medical history died of staphylococcal septicemia. The patient developed a sore throat, headaches, and furuncles on one leg and one arm within several days after riding a motorbike through sewage sludges applied nearby for mine reclamation purposes. A primary 


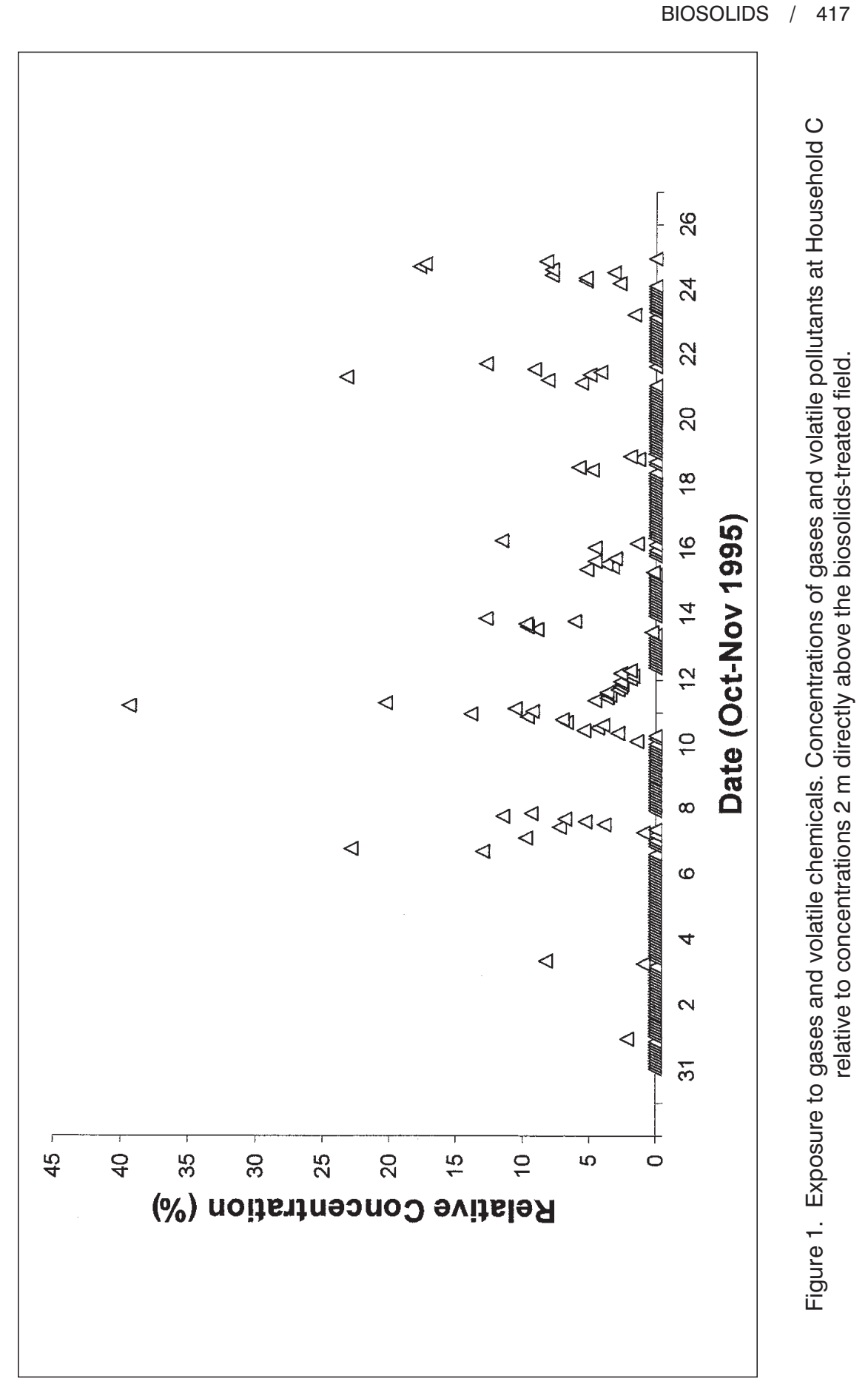


418 / LEWIS ET AL.

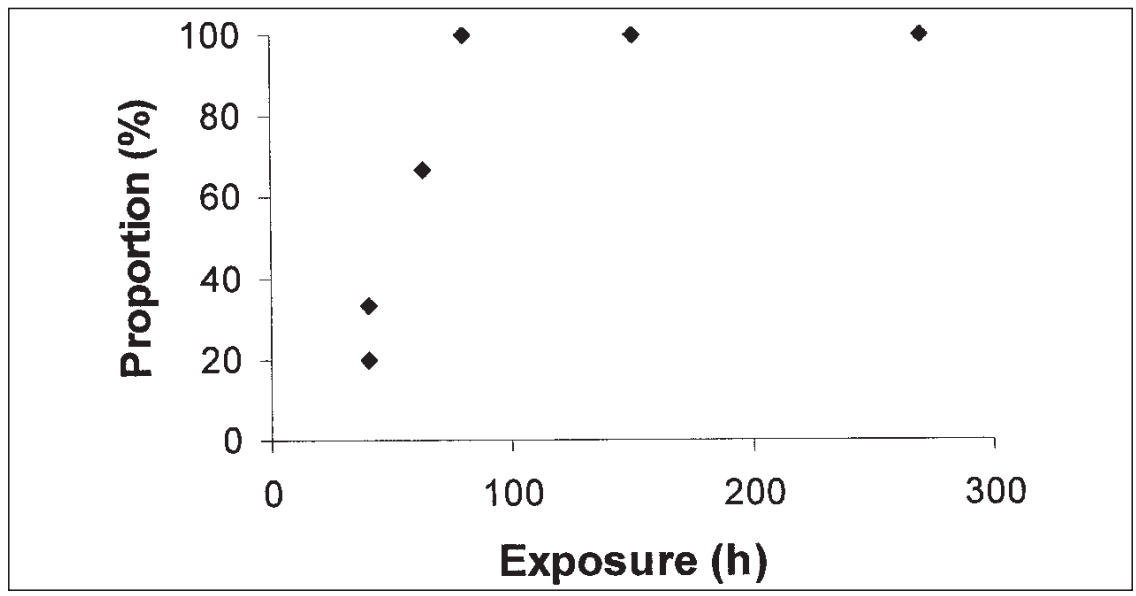

Figure 2. Dose-response relationship. Proportions of individuals experiencing symptoms in households versus exposure to gaseous and volatile pollutants from the biosolids-treated field.

care physician prescribed antibiotics and the patient was admitted to the hospital the following day with difficulty in breathing and high fever.

S. aureus was isolated from skin lesions and IV antibiotics were administered. The patient developed septicemia and expired six days after contacting the biosolids. Mine workers in the same area requested a health hazard evaluation after experiencing similar respiratory and skin irritation symptoms that they attributed to biosolids exposure.

The second mortality was associated with an outbreak of $S$. aureus in Robesonia, Pennsylvania. According to state records, Class B, lime-stabilized sewage sludges from a local wastewater treatment facility were applied to ten fields comprising a total of 300 acres. Applications began in 1988 and continued through December 1995. Sewage sludges were applied five times a week at a rate of approximately 1,300 tons (dry wt) per year.

Of nine individuals living in or frequenting the house where the outbreak occurred, eight developed $S$. aureus infections over a five-year period beginning in February 1993 (Table 2). The house was located across a paved road approximately $200 \mathrm{~m}$ from the treated field. Three individuals (Patients 1, 7, 8) were granted hunting rights on the farmland and frequently traversed treated areas during the application period.

Eight additional individuals lived in four other houses that were also located in close proximity to the field $(<50 \mathrm{~m})$. These individuals complained of odors, inundation with houseflies, and respiratory symptoms. They associated these 
Table 2. Outbreak of $S$. aureus in Robesonia, Pennsylvania ${ }^{a}$

\begin{tabular}{|c|c|c|c|c|}
\hline Patient & Onset of disease & Age/Sex & Occupancy & Presentation \\
\hline 1 & February 1993 & 15 & Resident & Furuncle $^{b}$ \\
\hline 2 & July/August 1993 & $87_{-}$ & Resident & Furuncle $^{c}$ \\
\hline 3 & July 1994 & 40 & Visitor & Furuncles $^{b, d}$ \\
\hline 4 & August 1994 & 66 & Visitor & Foliculitis \\
\hline 1 & March 1995 & 17 & Resident & Pneumonia \\
\hline 5 & June/July 1995 & 37 & Visitor & Furunclese \\
\hline 6 & August 1995 & 7 & Visitor & Furuncle $^{c}$ \\
\hline 7 & December 1995 & 16 & Resident & Furuncle $^{d}$ \\
\hline 8 & September/October 1997 & 46 & Resident & Furuncles ${ }^{f, g}$ \\
\hline
\end{tabular}

aRecurrent Staphylococcus aureus infections developed in a Robesonia, Pennsylvania household over a five-year period after Class B biosolids were applied several times a week on a yearly basis to a nearby farm. Patients 1,7 , and 8 correspond with Residents 39,40 , and 41 , respectively (Table 1). Patient 1 developed an $S$. aureus furuncle on one knee then, two years later, succumbed to $S$. aureus pneumonia. ${ }^{b}$ Knee ${ }^{C}$ Leg ${ }^{d}$ Thigh ${ }^{e}$ Nose, arm, abdomen, buttocks ${ }^{f}$ Neck, chin ${ }^{g}$ Chest

problems with application of biosolids; however, they could not recall having any infections.

Residents reported that feral cats occupying a barn near the treated field had to be destroyed after developing multiple boils and weeping sores after sewage sludge applications began. Similarly, residents at the New Hampshire site reported that one individual and numerous pets (dogs, cats) developed boils after sewage sludges were applied. Pets may have served as a reservoir of staphylococcal infections in these neighborhoods and, in some cases, transmitted their infections to humans.

Medical records were available for three of the four infected residents: Patients $1,3,8$. Patient 1 , a 17-year-old male with a history of excellent health, was treated for a furuncle of the knee in February1993 then succumbed to S. aureus pneumonia in March 1995 after contracting a rotavirus infection and viral pneumonia. Each of four relatives who frequented the house (e" $2 \mathrm{~d} / \mathrm{wk}$ ) was also infected with $S$. aureus. The first of these (Patient 3) developed furuncles concurrently with dermatophytic infections (identified as tinea cruris/tinea corpora). All but two individuals (Patients 6,7) sought medical attention. These patients were self-treated using antibiotics prescribed for other family members. The last S. aureus infection at Robesonia (Patient 8) occurred approximately two years after biosolids applications ceased. 
Overall, the prevalence of $S$. aureus infections in this study was approximately twenty-five times higher than infections among hospitalized patients, a recognized risk group for $S$. aureus [9].

\section{DISCUSSION}

Chemical irritants of concern with biosolids include endotoxins, lime, ammonia, and alkyl amines. These contaminants may cause allergic and nonallergic reactions that could contribute to broncho-obstructive and inflammatory responses [3]. The senior author and two accompanying individuals, for example, experienced coughing, burning eyes, burning throat, headaches, congestion and difficulty in breathing within $1 \mathrm{~h}$ while conducting a site visit in Menifee, California. The visit occurred during a time when residents were reporting these same symptoms. Although high winds were blowing sand from the treated fields, no odor was evident at that time. This experience argued against attributing the symptoms to odor-related psychosomatic responses, which are thought to play an important role in self-reported illnesses associated with human and animal waste-treatment operations [2].

The lower human colon is the primary reservoir for $S$. aureus; therefore, the organism is a common sewage contaminant. It is known to survive desiccation for days to weeks and can be aerially transmitted [10]. It tends to invade irritated tissue and infections are a common complication of diaper rash after prolonged contact with urine and feces [11,12]. Although it can be part of the natural skin and nasal microflora, risks of infection vary widely among different strains and increase with exposure to virulent strains from other sources. It is a leading cause of nosocomial pneumonia and surgical site and bloodstream infections [9]; however, the EPA considered it to be a low risk to public health with land applied sewage sludges [13].

In the case of recurrent $S$. aureus infections in Robesonia (Table 1), it was evident that a persistent source of $S$. aureus was present. It was unclear, however, whether the strain(s) responsible for the infections had a common environmental source lasting for several years or if certain individuals or pets became persistent carriers and continued to expose others even after land application ceased. Residents reported that tilling the heavily treated soil still, seven years later, draws large swarms of houseflies to the area.

A lack of any documented risk of staphylococcal infections among workers processing and handling wastewater and sewage sludges may reflect the fact that workers are more immunocompetent than the general population, or that adequate epidemiological studies have not been done. It may also reflect differences in exposure routes; or, it may suggest that incubation in the field can lead to increased concentrations or virulence of the organism.

Risks of infection with $S$. aureus may also depend on environmental processes that enhance the ability of sewage sludges to irritate the skin and respiratory tract. 
As gram negative bacteria die off after sludge application, endotoxin concentrations (a potential source of bronco-pulmonary irritation) increase. As sludges dry in the field, lime and other irritant chemicals become concentrated and, therefore, may be more irritating upon dermal contact and inhalation.

Federal guidelines advise wearing protective gear and exercising good personal hygiene when handling Class B biosolids or exposed to the aerosols $[6,14]$. The nature and timing of symptoms reported by residents suggest that steps should also be taken to protect the public from exposure to airborne contaminants from land application areas. Air-dispersion models, such as the one used in this study, could provide guidance in selecting application sites where exposure of residents would be minimal.

The Osceola Mills case, Robesonia outbreak, and the occurrence of staphylococcal infections among residents at other land application sites suggest that risks land application practices pose from these pathogens may be higher than expected. Chemical contaminants in sludges, which irritate the skin and mucous membranes, may be responsible for an increased host susceptibility.

Further research is needed to address illnesses among residents exposed to Class B biosolids, especially airborne dusts, and the role irritant chemicals may play in risks posed by low levels of pathogens.

\section{AUTHORS' CONTRIBUTIONS}

DL was responsible for the study's concept and design, supervised the study, participated in the analysis and interpretation of data, drafted the manuscript, and participated in the critical revision of the manuscript. DG supervised and participated in the data collection using air dispersion modeling, participated in the analysis and interpretation of that and other data, contributed to the technical support of the project, and participated in the critical revision of the manuscript. MN participated in the dispersion modeling, conducted the survey of selfreported symptoms, contributed to the computer support and data management of the project, and participated in the revision of the manuscript. SS supervised the isolation and identification of microbial isolates and contributed to the analysis and interpretation of that data. CP treated children living near land application sites in Menifee, California, and participated in the acquisition and interpretation of medical data.

\section{ACKNOWLEDGMENTS}

Support in identifying microbial isolates was provided by Pamela Currin, Eric Wommack (DNA sequencing of Brevundimonas diminuta), G. E. Michaels, Scott Russell, and Lynda Jones. 


\section{DISCLAIMER}

This work was conducted in part under an Intergovernmental Personnel Act assignment between the U.S. Environmental Protection Agency (EPA or Agency) and the University of Georgia. Although this article has been subjected to an Agency review process and approved for publication, the views expressed are those of the authors and do not necessarily reflect the views or policies of the EPA. Mention of trade names or commercial products does not constitute an endorsement or recommendation for use.

Technical assistance with air dispersion modeling was provided by Dennis G. Atkinson.

\section{EDITOR'S NOTE}

Reprint: Interactions of Pathogens and Irritant Chemicals in LandApplied Sewage Sludges (Biosolids), David L. Lewis, David K. Gattie, Marc E. Novak, Susan Sanchez, and Charles Pumphrey, BMC Public Health 2002, 2:11 (28 June 2002). Available online at http://www.biomedcentral. com/1471-2458/2/11.

\section{REFERENCES}

1. D. Lewis and D. Gattie, Pathogen Risks from Applying Sewage Sludge to Land, Environmental Science Technology, 36:13, pp. 286A-293A, 2002.

2. S. S. Schiffman, J.M. Walker, P. Dalton, T. S. Lorig, J. H. Raymer, D. Shusterman, and C. M. Williams, Potential Health Effects of Odor from Animal Operations, Wastewater Treatment Facilities, and Recycling Byproducts, Journal of Agromedicine, 7:1, pp. 1-80, 2000.

3. S. Norn, P. Clementsen, K. S. Kristensen, P. S. Skov, H. Bisgaard, and S. Gravensen, Examination of Mechanisms Responsible for Organic Dust-Related DiseasesMediator Release Induced by Microorganisms-A Review, Indoor Air, 4:4, pp. 217-222, 1994.

4. Committee on the Use of Treated Municipal Wastewater Effluent and Sludge in the Production of Crops for Human Consumption, Use of Reclaimed Water and Sludge in Food Crop Production, Water Science and Technology Board, National Academy of Sciences Press, Washington, 1996.

5. P. T. Gregersen, K. Grunnet, S. A. Uldum, B. H. Anderson, and H. Madson, Pontiac Fever at a Sewage Treatment Plant in the Food Industry, Scandinavian Journal of Work and Environmental Health, 25:3, pp. 291-295, 1999 [PubMed Abstract].

6. Centers for Disease Control \& Prevention, National Institute for Occupational Health \& Safety (NIOSH), Health Hazard Evaluation Report No. 98-0118-2748.

7. R. C. Dorn, C. S. Reddy, D. N. Lamphere, J. V. Gaeuman, and R. Lanese, Municipal Sewage Sludge Application on Ohio Farms: Health Effects, Environmental Research, 38, pp. 332-359, 1985 [PubMed Abstract]. 
8. Industrial Source Complex (ISC3) Dispersion Model, ISCST3 Version 99155, Office of Air Quality Planning and Emissions, Monitoring, and Analysis Standards Division, EPA-4541B-95-0032, U.S. Environmental Protection Agency: Research Triangle Park, North Carolina, 1995.

9. R. J. Rubin, C. A. Harrington, A. Poon, K. Dietrich, J. A. Greene, and A. Moiduddin, The Economic Impact of Staphylococcus aureus in New York City Hospitals, Emergency Infectious Diseases, 5, pp. 9-17, 1999 [PubMed Abstract].

10. R. J. Sherertz, S. Bassetti, and B. Bassetti-Wyss, "Cloud" Health-Care Workers. Emergency Infectious Diseases, 7, pp. 241-244, 2001 [PubMed Abstract].

11. J. J. Leyden and A. M. Kligman, The Role of Microorganisms in Diaper Dermatitis. Archives of Dermatology, 114:1, pp. 56-59, 1978 [PubMed Abstract].

12. I. Brook, Microbiology of Secondarily Infected Diaper Dermatitis, International Journal of Dermatology, 31, pp. 700-702, 1992 [PubMed Abstract].

13. U.S. Environmental Protection Agency, Preliminary Risk Assessment for Bacteria in Municipal Sewage Sludge Applied to Land, EPA/600/6-91/006, 1991.

14. U.S. Department of Health and Human Services, Workers Exposed to Class B Biosolids During and After Field Application, DHHS (NIOSH) Publication No. 158, 2000 .

Direct reprint requests to:

David L. Lewis, Ph.D.

Department of Marine Sciences

University of Georgia

Athens, GA 30602 